\title{
The Research of the Industry of Coupons Services in Russia
}

\author{
Pavel Mozgunov ${ }^{1, *}$, Karina Kuznecova ${ }^{2}$ \\ ${ }^{1}$ Faculty of Economics, National Research University Higher School of Economics, Faculty of Economics, Moscow, Russia \\ ${ }^{2}$ Department of microeconomic analysis, National Research University Higher School of Economics, Faculty of Economics, Moscow, \\ Russia \\ *Corresponding Author: pmozgunov@gmail.com
}

Copyright (C) 2013 Horizon Research Publishing All rights reserved.

\begin{abstract}
The purpose of this new study was to make a full and detailed profile of the typical Russian coupon site user. Moreover, the main factors that can influence decision of purchasing of coupon were determined and some of them were studied more detailed. The study involved 665 Internet users aged from 17 years living at the time of the interview in Moscow. The findings of the study may be useful to firms that are planning to use the coupon services. The study concludes that a typical Russian coupon user can be described as follows: a female aged 20 to 41 years, with higher education, most likely unmarried, working, with an average income ranging from 12,500 to 60,000 rubles The relation between the mean time to the venue of leisure and consumer income as well as time-income elasticity are among the most important findings for firms. It has been proved that the connection between these indicators is statistically significant, which means that income can strongly influence an individual's decision to purchase a particular coupon, depending on the average time the individual in question is willing to spend on getting to the venue of entertainment.
\end{abstract}

Keywords Consumer Behavior, Coupon Service, Propensity of Purchasing, Income Elasticity

\section{Introduction}

Purchasing goods and services at a discount ranging from 50 to $90 \%$ through coupons has been the major trend in the global Internet community -for the past five years. These coupons are actively used both by the consumers and the producers, whereby the latter are interested in the coupon services as new means of promoting their products on the market. Coupon services, which give the opportunity to buy virtually any product or any service at a discount flooded the Internet and instantly became popular among Internet users.

Unexpected and unpredictable for many the 2008 global financial crisis gave an impetus to a more intensive development of behavioral economics. In this regard, coupon services seen as a new tool to influence consumer behavior are of great scientific interest. How do coupons affect the consumer if at all? What caused the incredibly rapid growth of coupon services, and can coupons attract new customers? These are the main questions to guide us within the framework of the given study.

The development of coupon services is a fairly new phenomenon, both in Russia and in the world at large. Even in spite of the rapid development of the industry, it has not yet been properly studied, either from the consumer perspective or from the producers' stand. However, the United States stands out in this respect, where there have been several studies of the effect of coupons on business alongside with several surveys conducted among the buyers of coupons, but, nevertheless there is no full understanding of the industry even in the US. As a rule, one survey sheds light onto a fraction of the entire picture only, and no extensive research on the part of the consumer has been carried out. In Russia, on the other hand, the impact of coupon sites on consumer behavior has not been studied scientifically at all. This very subject is of great interest to the media, which, unfortunately, are not always capable of correctly analyzing the data available. The coupon services themselves use only subjective data in all of the official statements, leaving data extraction methodology unknown, which yields any assessments based on those statements subject to investigation. Thus getting even the basic idea of the industry has been quite a challenge. Just as in the US, up until April 2012 there has been no complete understanding of the typical consumer, the propensity of consumers to purchase coupons, or the possible "trends" of consumer behavior in the industry in Russia. Namely, this has caused interest to independently investigate the matter and try to compare the obtained results with the coupon sites as well as to assess the impact of coupons on consumer choice, which is the main objective of this paper.

Although the coupons in question deal mainly with the entertainment services, as will follow from the study, practically all the findings of this study are applicable to any type of coupons. 


\section{Review of Previous Studies}

As of the early 2012, there were only few studies related to the coupon services available. Solid research from the producer perspective was conducted at the Harvard Business School by Edelman, B., Jaffe, S., \& Duke Kominers, $\mathrm{S}^{1}$, while a comprehensive study on the part of the consumers still did not exist in the U.S. As mentioned before, none of the Russia scholars took a holistic approach to studying the industry until the April 2012, when the paper of Pavel Mozgunov (2012) draws on the conclusions and findings obtained through a survey conducted in March 2012. In his article, «Analyzing coupon trade development. International experience. Russian features» ${ }^{2}$, the formation of the main differences in this sector in Russia and the U.S., as the country of origin for this particular service was analyzed. The paper reviewed the industry on the consumer side, namely, looking for answers to these questions:

- How many people know about the coupon sites and buy coupons?

- What is the source of information about coupon services?

- What types of coupons do Russian consumers prefer?

- What determines the choice of the consumer of a coupon service, that is, what aspects are important for the majority of users.

- Special attention was paid to those groups of consumers who do not use coupons at the moment, those who have never used such services, and the group of people who have stopped buying coupons at all.

Having answered all these questions, a suspicion arose that there may be effects coupons have on consumer choice thus a hypothesis has been tested that a coupon can control the behavior of the consumer.

Receiving certain prerequisites that the coupon may influence the behavior of consumers, we have tested a corresponding hypothesis. The paper assumed that there may be a spontaneous purchase of a good, whereby something 'catches the consumer's eye' at the very moment of viewing. While looking for a product they have in mind consumers pay attention to another product seeing it sold through a coupon service at a significant discount. Products or services, may not coincide with the wishes and plans of the consumer viewing the site, or in the case of services, they do not overlap with his hobbies. Momentary desire, an impulse guide consumers like this. According to James Berger ${ }^{3}$,

1Edelman, B., Jaffe, S., \& Duke Kominers, S. (2011, October 19). To Groupon or not to Groupon: The Profitability of Deep Discounts. In http://www.hbs.edu. from

http://www.hbs.edu/faculty/Publication\%20Files/11-063.pdf

2Mozgunov, P. (2012). «Analyzing coupon trade development. International experience. Russian features» . In Collection of the best works of students, graduate students and young scientists of the Lomonosov-2012 conference. Section "Innovative Economy and Econometrics". Moscow, Russia: Moscow State University.

3Berger, J. T. (2011, July). The Groupon Phenomenon - Is It Sustainable? In http://www.wiglafjournal.com. fromhttp://www.wiglafjournal.com/mark eting/2011/07/the-groupon-phenomenon- $\%$ E2\%80\%94-is-it-sustainable/ work has been verified, spontaneity of purchase substantially reduces the likelihood that the consumer will become a regular customer, which is the ultimate goal of the producer using coupon services. However, if the spontaneity of purchase does not necessarily affect customer loyalty, the following finding helped answer this question. Developing the assumptions that the coupon is a very inefficient tool to achieve customer loyalty to the researcher tested the hypothesis that people purchasing a product or a service at a discount, know in advance that they will not be able to afford the same product at full price. This means that this set without a coupon lies far beyond their budget restriction, whereby one can assume, that this reduces the likelihood that the consumer will become a loyal customer.

Another estimation within the framework of the research was the percentage of consumers who are more likely to be regular customers for a firm, being attracted by the coupon. A prerequisite for this would be the simultaneous execution of the two theses above. That is, the consumer does not purchase coupons on goods or services that are not available to him without a discount, and does not make spontaneous purchases online. To identify the same proportion, a number of other clarifying questions was used, aimed at finding the number of consumers that have already returned (or are willing to return) to the same company, but without the coupon. The hypothesis of the effects described was confirmed in the course of the work, and according to various estimates, only $3-4 \%$ of all buyers of coupons can potentially become loyal customers of goods or services produced by a certain firm. It is difficult to say how high or how low this estimate is in terms of consumer attraction through coupons. However, this figure has not been made public by any coupon service, so it can be very useful in assessing the effectiveness of cooperation of companies with coupon sites.

The confirmation of the hypothesis that coupons do affect customer choice triggered further research.

It was within the framework of the new studies that a group of Russian consumers was identified more likely to be influenced by a coupon. The purpose of this study was to make a full and detailed profile of the typical Russian coupon site user.

The process of determining the main characteristics of such a group was divided into several relatively independent stages.

The first stage was to test the hypothesis that, for certain groups of consumers a coupon is a normal good, whereas for others it is inferior. As a consequence, those consumers that see coupons as a normal good, are potentially more prone to buying coupons, and at the same time, the coupon can have a significant influence on the final decision and the choice of a product or service. As mentioned above, in this study the main focus was placed on the coupons for entertainment services, so it was necessary to take into account the opportunity costs of leisure. The resulting curve is the "price-consumption" curve, showing the relation between the salary and the number of hours for leisure was used to 
interpret the results. The data on the number of coupons purchased per consumer in each income group is used to calculate the arc elasticity of demand for coupons on entertainment services depending on income.

The second stage, independent from the first stage, was to find a general relative tendency coefficient of each consumer to purchase coupons. It was obtained based on the information from customers about their previous purchases. It is called relative mainly because it has no information on the propensity of each individual customer to purchase coupons in itself, but rather helps compare the tendency of two or more users of coupon sites. it is called General, on the ground, that it is a weighted sum of other four coefficients, also obtained in this study. The following factors that influence the overall tendency of consumers in general were identified in the course of the study.

- The tendency of the individual to the first purchase $\left(\mathrm{k}_{1}\right)$

- The tendency of the individual to the second purchase $\left(\mathrm{k}_{2}\right)$

- Total number of coupons purchased $\left(\mathrm{k}_{3}\right)$

- Overall efficiency $\left(\mathrm{k}_{4}\right)$ - how many purchases are made per one visit to a website.

This coefficient is one of the main findings of this study and will mainly help evaluate which consumer group is more inclined to buy and use coupons. The results obtained at the first stage, of identifying the income groups, for which the coupon is a normal good have been used as an estimate whether the coefficient is at all valid in indicating the tendency to purchase a coupon.

The final phase was to study the problem of the factors that are important to consumers in the choice of the coupon. Is there a general trend consumers use to assess the conditions of the coupon or not? Moreover, the researchers have identified the factors that are more likely to "put off" consumers from purchasing the coupon. Among them were the following:

- A strict deadline or expiration date of a coupon;

- Leisure venue;

- Pre-registration requirements;

- Restrictions on the amount of coupons one can buy;

- Coupon submission form.

The "chosen leisure venue" factor has been studied separately and in more detail. The way consumers assess the time spent on travel from the house to the place of leisure is the main issue in this part of the work. The hypothesis is that consumers with different income levels have different attitudes to this aspect. The group of consumers with relatively high incomes is not ready to take the time to travel even with a promise of a large discount, which in a large metropolitan area, such as Moscow is quite difficult. Information was obtained on the amount of time consumers are willing to spend on travel depending on their income. Other factors that may influence decision-making about the time spent on travel along with the income are the tendency to buying coupons within a certain group, and the percentage of consumers in the group with a personal vehicle.

\section{Data}

The study involved 665 Internet users aged from 17 years living at the time of the interview in Moscow. The survey was conducted on behalf of the Department of microeconomic analysis of HSE over the period from March 1 to March 31, 2012. The total age group covered ranged from 17 to 56 years. The format of the questionnaire has been approved by the Head of the Department of Sociology of the St. Petersburg branch of HSE - Professor A.A.Veyher. According to the All Russian Center for Public Opinion Studies - VTsIOM ${ }^{4}$ - in $2010,70 \%$ of all Internet users fell into the age group of 18-24 years. One of the necessary conditions for an unbiased sample was to preserve the proportions of the given study, as the main audience of coupon sites is the Internet users. This proportion of consumers in the age group 18-24 has been saved. The survey was optimized to be as informative as possible and at the same time easy and quick to fill out by the respondents. The survey can be completed electronically or in paper form. According to the results, we can say that the survey covered all consumer groups relevant for the coupon sites. Due to the fact that the survey was in the public domain, both in print and in electronic form, we can say that the sample is representative thanks to the format of the interview.

\section{Methodology}

Initially, it should be noted that all the information gathered from the survey data was adjusted using duplicate questions to eliminate deliberate wrong answers.

It is worth noting that in this part of the study the assumption of rationality of the consumers in question is key. The representative agent was considered based on income, assuming all other values remained unchanged. It is important to emphasize that only working respondents were included in this model. To determine the income group, for which the coupon is an inferior good, the following method applied. Initially, all the individuals were divided into income groups, according to the level of monthly income in rubles. Then we found out the total number of coupons purchased by individuals in each group, after which the value was normalized against the number of consumers. The data obtained were plotted according to the relation of the amount of coupons per customer to the average income of the group. After that, the same data were used to calculate arc elasticity at each income interval.

$$
\varepsilon_{I}^{d}=\left[\left(Q_{2}-Q_{1}\right) /\left(Q_{2}+Q_{1}\right)\right]:\left[\left(I_{2}-I_{1}\right) /\left(I_{2}+I_{1}\right)\right.
$$

To interpret the results we used a graph of the working-time depending on the income for the representative individual. This stage of analysis was necessary since the paper studies coupons for entertainment services, and

4All Russian Center for Public Opinion Studies . Press release №1466 (06/04/2010). All Russian Center for Public Opinion Studies . Moscow: n.p., 2010. N. pag. Web. 2010.

<http://old.wciom.ru/arkhiv/tematicheskii-arkhiv/item/single/13386.html>. 
entertainment is part of leisure, therefore it is necessary to take into account its opportunity cost. The model was built according to how much entertainment services each person is ready to consume. It was suggested that the individual determines his labor supply based on the following dependence $L=12-l$, where 12 is the number of hours that he decides to allocate between work and leisure, 1 being the time available for leisure. it is crucial to see the dynamics of change in each of the sections of changes in income. The two models gave grounds to assess the type of goods in relation to the change in income of the individual thus serving as an explanation of the behavior of the representative individual.

The next step was to calculate the total relative tendency coefficient of consumers to purchase coupons. This coefficient was calculated as a weighted sum of the other four factors.

The relative tendency coefficient $(\mathrm{k})$ is calculated as

$$
\begin{gathered}
k_{\text {general }}=\sum_{i=1}^{4} a_{i} * k_{i} \\
a_{i}-\text { weights; } a_{i}>0, ; \sum_{i=1}^{4} a_{i}=1 ; 0 \leq k_{i} \leq 1
\end{gathered}
$$

$k_{i}$ - the corresponding coefficient.

Table 1. Coefficient 1

\begin{tabular}{|c|c|}
\hline \multicolumn{2}{|c|}{ K1=0,0961-0,023days } \\
\hline Days & Value of k1 \\
\hline 1 & 1 \\
\hline 2 & 0,8601 \\
\hline 5 & 0,7911 \\
\hline 7 & 0,7451 \\
\hline 21 & 0,4231 \\
\hline 30 & 0,2161 \\
\hline 40 & 0,05 \\
\hline
\end{tabular}

The first factor $-\mathrm{k}_{1}$ is the tendency of the individual to the first purchase. Individuals were asked in what period of time after they learned about the coupon sites, they made the first purchase. Knowing the gaps between registration and first purchased coupon, one can judge whether the consumer was inclined to try to use the coupon.it is, however, necessary to consider the fact that the considered consumer could have been lead on by his own curiosity and a desire to try out the new service, for this reason we cannot perceive this factor as fully defining the tendency, but neither can it be ruled out. Therefore, the weight of this factor was set at a relatively low level $\mathrm{a}_{1}=0.125$. The coefficient was calculated as follows, if the number of days that a consumer takes before the first purchase was equal to one day, then $\mathrm{k}_{1}=1$, and if it was 40 , $\mathrm{k}_{1}=0,05$. For the two data points we restored a linear equation, transferring the number of days spent on decision-making into the $\mathrm{k}_{1}$ coefficient. The following approximate values for each of the indicators were received (Table 1).

The second factor- $\mathrm{k}_{2}$ is the tendency of the individual to the second purchase. It was calculated similarly to the $\mathrm{k}_{1}$ coefficient. In this case, the evaluation period was the time it takes for an individual to make a decision about buying a second coupon, after the first. And since fewer days correspond to a greater propensity, and more correspond to less, the coefficient would have similar dynamics. However, it also cannot be seen as the only one which explains the overall tendency. The weight of this factor will be rather small, because it may have an effect of the successful experience of the first coupon use and therefore show the confidence in coupon services, but this is not to say the long-term propensity to consume is fully explained through it, hence $\mathrm{a}_{2}=0,125$. The maximum amount of time to make a decision was set at 30 days, so we obtained the following values (Table 2):

Table 2. Coefficient 2

\begin{tabular}{|c|c|}
\hline \multicolumn{2}{|c|}{$\mathrm{k} 2=0,9451-0,0306$ days } \\
\hline Days & Value of $\mathrm{k} 2$ \\
\hline 1 & 1 \\
\hline 2 & 0,8839 \\
\hline 5 & 0,7921 \\
\hline 7 & 0,7309 \\
\hline 21 & 0,3025 \\
\hline 30 & 0,05 \\
\hline
\end{tabular}

Table 3. Coefficient 3

\begin{tabular}{|c|c|}
\hline \multicolumn{2}{|c|}{$\mathrm{k} 3=0,0801+0,0319$ coupons } \\
\hline Amount of coupon & Value of $\mathrm{k} 3$ \\
\hline 1 & 0,05 \\
\hline 3 & 0,1758 \\
\hline 9 & 0,3672 \\
\hline 14 & 0,5267 \\
\hline 25 & 0,8776 \\
\hline 30 & 1 \\
\hline
\end{tabular}

The third coefficient $-\mathrm{k}_{3}$ is the number of purchased coupons. But since it does not reflect the time that the user is on the site, then this figure will also be taken with a little weight, and $\mathrm{a}_{3}=0.15$. The values are calculated similarly to the previous ones, with the difference that the relation described is positive - the more coupons consumers buy, the higher the coefficient. That is to say 1 purchased coupon corresponds to the rate of 0.05 , and 30 or more to the value of 1. Thus, we obtained the following values (Table 3 ).

And the last factor- $\mathrm{k}_{4}$ is the general performance. This coefficient was calculated by dividing the frequency of shopping for coupons and the frequency of the coupon site visits per individual. Thus, the ratio shows the number of coupons per one visit. Assuming that one visit can lead to no more than one coupon purchase, this ratio also varies from 0 
to 1 . At the same time, this factor is the most informative. Since this figure manifests the desire and the willingness of consumers to buy a coupon, this figure was the most significant factor in the overall propensity and hence $\mathrm{a}_{4}=0,6$. Thus, the

$$
k_{\text {general }}=0.6 * k_{4}+0.125 * k_{2}+0.15 * k_{3}+0.125 * k_{1}
$$

The given coefficient was calculated for each individual separately and the group that is more inclined, in our opinion, to purchase coupons was singled out against the resulting mean value. .

\section{Dependence of the Amount of Time Spent on the Road and the Income of the Individual}

The behavior of all individuals is represented through the behavior of the representative individual. All other parameters are unchanged apart from income, sex and coefficient of propensity. The last two variables were selected as possibly capable, of influencing consumer decisions. But our goal is to see the effect of income on the amount of time that individuals are willing to spend on travel to the leisure venue and we cannot avoid these variables. We will build simple ols-regression model of time depending 3 variables above. However, it is necessary to determine a specification of our model correct. Reset-Ramsey test showed that it is impossible to use linear specification and as in many other consumer researches we took the logarithm of variable «income». As a result t-statistics and F-statistics increased, so we stop at this specification. Moreover, there is no multicorrelation between variables, and heteroscedasticity tests (White, Breusha-Padana-Godfri) has shown that hypothesis that residuals are homoscedasticity is not rejected. It makes possible not to get effective estimates of regression.

\section{Results}

\subsection{Coupon - inferior VS Normal Good}

Following the logic of the methodology described above and the study has identified which income groups consider coupons inferior goods and which, on the contrary, see them as normal. The results on the dependence of the average number of coupons per customer on the income are as follows (Figure 1).

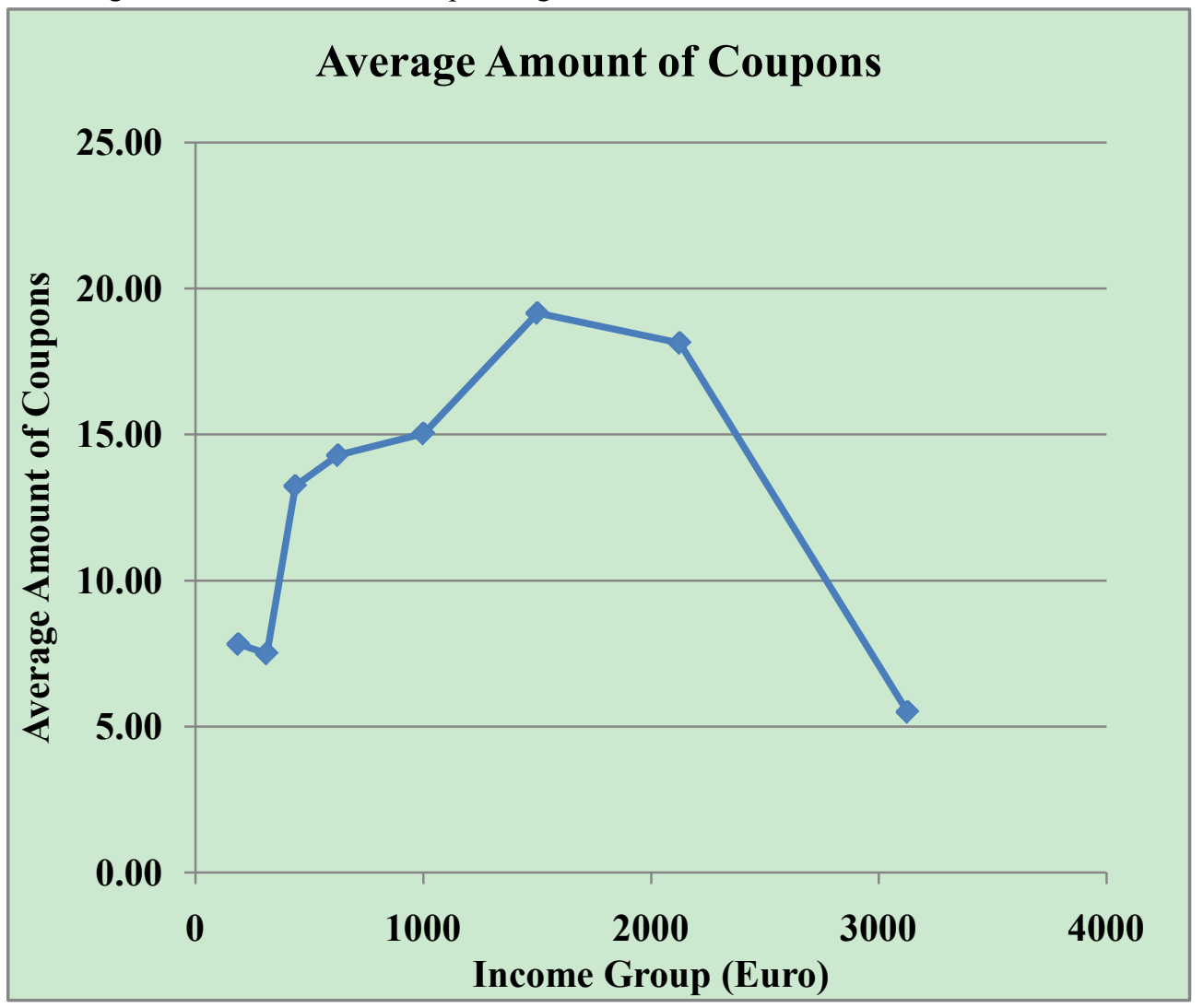

Figure 1. Average amount of coupon per consumer in each income group, Russia, 2012 
The Figure 1 shows the average number of coupons purchased in each group. Then, using the data at hand arc elasticity was calculated. The results are shown in the Table 4:

Table 4. Income elasticity.

\begin{tabular}{|c|c|}
\hline Income group (in Euro) & Elasticity \\
\hline $62,5-187,5$ & $-0,354$ \\
\hline $187,5-312,5$ & 1,022 \\
\hline $312,5-562,5$ & 0,425 \\
\hline $562,5-1000$ & 1,519 \\
\hline $1000-1875$ & $-0,142$ \\
\hline $1875-3125$ & $-1,79$ \\
\hline
\end{tabular}

To properly interpret the results we constructed a curve showing the relationship of the individual labor supply and the individual income per hour. Thus we arrive at the "individual labor supply curve" below (Figure 2).

Numbers on the chart mark the number of hours allocated to work. As you can see, at low wages (less than 50 rubles (1,25 Euro) per hour) the labor supply curve has a positive slope, which means that the working time for a given point is a normal good, whereas leisure is inferior. When wages exceed 50 rubles (1, 25 Euro), the working time becomes an inferior good, and leisure turns into a normal one.

Let us turn to the actual interpretation of the first graph. As expected for groups with the income of over 50,000 rubles (1250 Euros) a month a coupon is an inferior good. This is due to the fact that people when comparing the cost of the search on the website and the products at a discount and the income that they can get over the same amount of time, choose the latter, because one hour of their working time is relatively expensive. Even despite the fact that for the groups of high-income leisure is a normal good, consumers will buy fewer coupons as the income rises. It was also found that coupons for entertainment services are an inferior good for consumers with very low income. This effect is due to the fact that for an individual with a small income, leisure itself is an inferior good and therefore an increase in income, will lead to more work, yielding entertainment coupons useless. For consumers with an income of 5,000 (125 Euro) to 50,000 rubles (1250 Euro), a coupon is a normal good, which means an increase of income, they start using more coupons for entertainment services.

\subsection{Propensity to Purchase Coupons}

The next step was to identify the group most inclined to purchase coupons based on the above propensity coefficient:

$$
\mathrm{K}_{\text {generalpropensity }}=0,6 \mathrm{k}_{4}+0,125 \mathrm{k}_{2}+0,15 \mathrm{k}_{3}+0,125 \mathrm{k}_{1}
$$

This coefficient was calculated for each individual separately. The average coefficient being: $\mathrm{K}_{\text {average }}=0.348$. Those individuals who have an above average tendency coefficient were identified as the most inclined to purchase coupons. According to this methodology, the typical Russian coupon user can be described as follows: the study revealed that women are most likely to use coupons (73\%), aged 20 to $41(75 \%)$, with higher education (47\%), likely unmarried $(53.3 \%)$, working $(50 \%)$, with an average income from 12,500 to 60,000 rubles

Since each individual firm knows its target audience and the typical consumer then having the information about conditional coefficients propensity is a relatively reliable predictor of the success of coupon promotion.

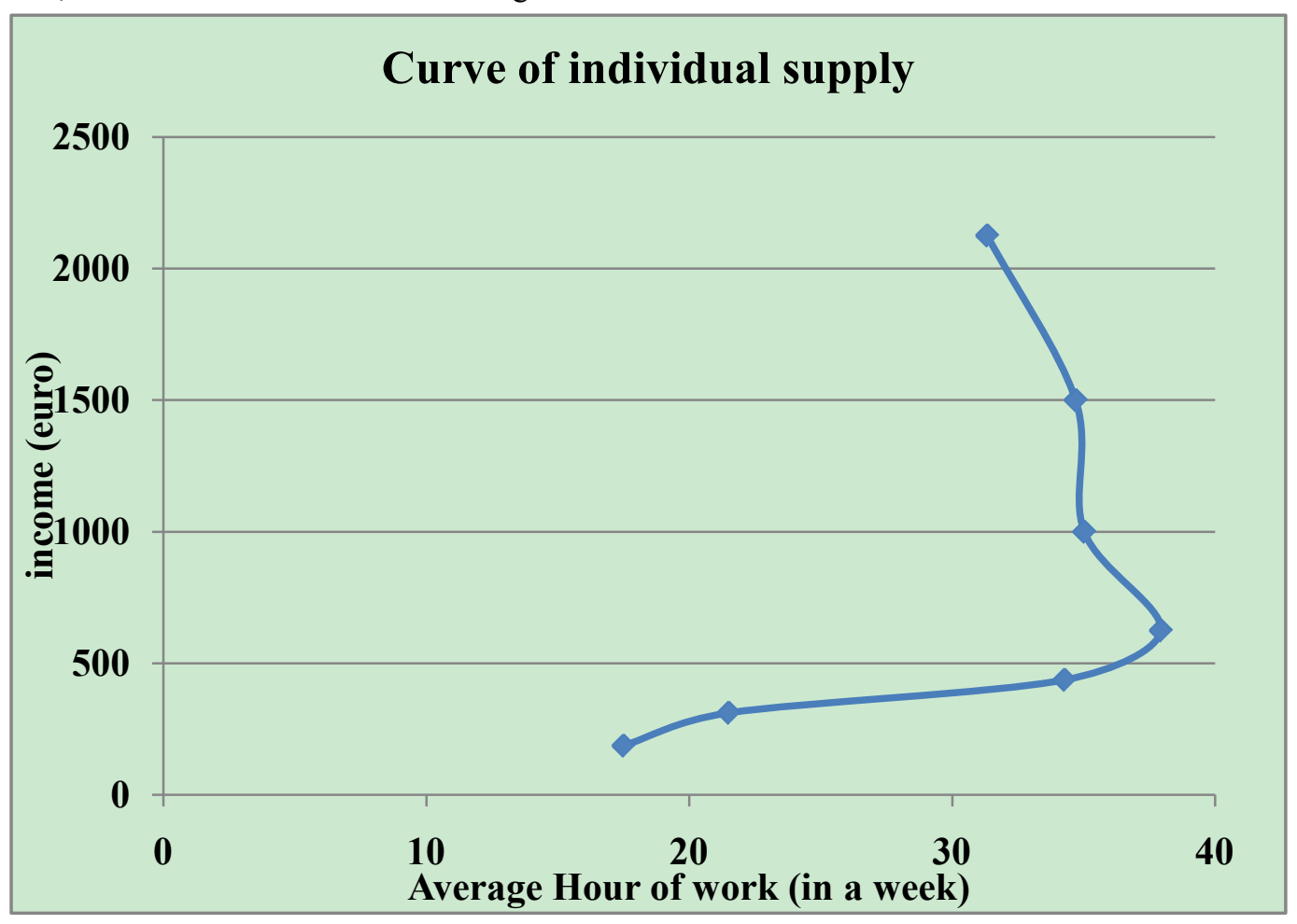

Figure 2. Curve of individual supply 


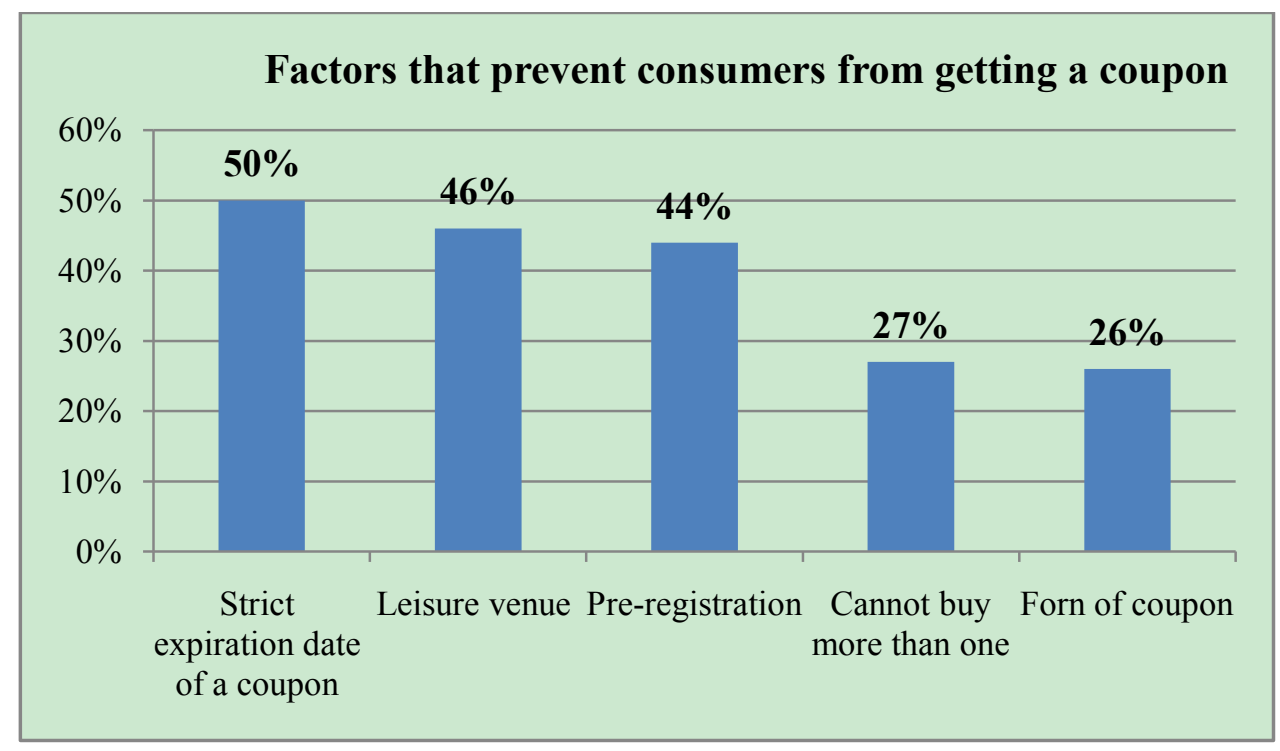

Figure 3. Factors that prevent consumers from getting a coupon

\subsection{The Relationship of Income and Time Spent on the Road}

In conclusion, the study singled out a number of factors that can influence the choice of the consumer, but rather determine the appeal of the coupon itself. This part of the work may be useful for practical application of companies that are going to work with coupon services to predict the effectiveness of coupon promotion more accurately. The first step is to define the factors that prevent consumers from getting a coupon, whereby the most important of these factors were identified. Respondents were asked to mark all the answers that apply, the results can be seen below (Figure 3).

As you can see, a strict expiration date of a coupon is one of the most common factors that prevent consumers from purchasing a coupon - nearly half of all respondents (49.61\%) marked this option. Almost the same number of respondents marked options "leisure venue" and "Pre-registration"- 46\% and $44 \%$, respectively. The study of leisure venue was a further specific focal point of the research.

According to information available through the method described above, a regression model was built examining both the relation between the average amount of time spent on travel to the venue and logarithm of income, sex and coefficient of propensity. The following results were got (Table 5):

Table 5. Regression's results

\begin{tabular}{|c|c|c|}
\hline R adjusted & 0,07677 \\
\hline & coefficient & $p$-value \\
\hline b0 & 157,563 & 0,00012 \\
\hline sex & 17,8958 & 0,03775 \\
\hline LN_income & $-8,3834$ & 0,03476 \\
\hline $\mathrm{k}$ & $-43,178$ & 0,03617 \\
\hline & & \\
\hline$F$ & $p$-value & \\
\hline 4,57319 & 0,00419 & \\
\hline
\end{tabular}

It can be seen from the graph that model is significant on the level 0,01 and this model can explain near $8 \%$ of all variance of time, consumers are ready to spend on the road. As it was suggested, there is negative relation beet time and income. It means that consumers are ready to spend less time for the road if them income increased. Also it was found and men are ready to spend average 18 minutes more for getting to the service than women. And consumers with higher level of propensity to purchase coupon are ready to ride less to service. To compare effects and find elasticity, we find new ols-estimates of regression of logarithm of depending and independent variables (Table 6).

Table 6. Elasticity

\begin{tabular}{|c|c|}
\hline & Elasticity \\
\hline ln_income & $-1,17451$ \\
\hline $\mathrm{k}$ & $-0,28917$ \\
\hline
\end{tabular}

According to the regression the elasticity was calculated at $\mathrm{E}=-1.1745$ (Table 6), which means that the time on travel to the leisure venue of the coupon is an inferior good. These models can be used effectively by small businesses that are planning to cooperate with online coupon services, because each particular firm, knowing its typical consumer, and the accessibility of the leisure venue can predict the effectiveness of the use of coupons in promoting their products or services. Moreover, logarithm of income effects a time for the road much more than the coefficient of propensity.

\subsection{Conclusion and Findings}

This study arrived at a number of findings new for the Russian market, and was in itself one of the first attempts at comprehensive micro-economic analysis of the behavior of consumers in terms of purchasing goods and services through coupon sites as well as the impact of coupons on 
different groups of consumers. The findings of the study may be useful to firms that are planning to use the coupon services and want to assess consumer attraction through coupons more effectively. two independent methods identified the group of individuals who are most likely to become regular buyers of coupons. The findings of both models do not contradict each other, but rather complement one another. The study concludes that a typical Russian coupon user can be described as follows: a female aged 20 to 41 years, with higher education, most likely unmarried, working, with an average income ranging from 12,500 to 60,000 rubles

The relation between the mean time to the venue of leisure and consumer income as well as time-income elasticity (sensitivity) are among the most important findings for firms.. It has been proved that the connection between these indicators is statistically significant, which means that income can strongly influence an individual's decision to purchase a particular coupon, depending on the average time the individual in question is willing to spend on getting to the venue of entertainment. Due to the fact that each firm knows which customers it is targeting, with the help of these models it can be predict with a certain probability whether the coupon is really effective in terms of attracting customers through collaboration with a coupon service, in the sense of how many customers they can attract through collaboration with a coupon service.

Opportunities for further research along the lines of the current study are abundant. Moreover, the two studies carried out may serve as a sufficient basis for further development of the subject area. One of the options to expand the study, is mapping the possible consumer decision-making patterns, and based on the data designing a 'consumer behavior manual', showing at what point and how the coupon starts to affect the decision taken by the consumer.

\section{REFERENCES}

[1] Schiffman, L. G., \& Kanuk, L. L. (2012). Consumer Bbehaviour. A European outlook (Second ed.). N.p.: Person Education Limited.

[2] All Russian Center for Public Opinion Studies . Press release №1466 (06/04/2010). All Russian Center for Public Opinion Studies . Moscow: n.p., 2010. N. pag. Web. 2010. $<$ http://old.wciom.ru/arkhiv/tematicheskii-arkhiv/item/single /13386.html>.

[3] Berger, J. T. (2011, July). The Groupon Phenomenon - Is It Sustainable?. In http://www.wiglafjournal.com. Retrieved April, 2012, from http://www.wiglafjournal.com/marketing/ 2011/07/the-groupon-phenomenon-\%E2\%80\%94-is-it-sustai nable/

[4] Edelman, B., Jaffe, S., \& Duke Kominers, S. (2011, October 19). To Groupon or not to Groupon: The Profitability of Deep Discounts. In http://www.hbs.edu. Retrieved April, 2012, from http://www.hbs.edu/faculty/Publication\%20Files/11-06 3.pdf

[5] Mozgunov, P. (2012). «Analyzing coupon trade development. International experience. Russian features». In Collection of the best works of students, graduate students and young scientists of the Lomonosov-2012 conference. Section "Innovative Economy and Econometrics". Moscow, Russia: Moscow State University.

[6] Nobel, C. (2012). The Groupon Phenomenon - Is It Sustainable?. In http://www.hbs.edu. Retrieved 2012, from http://hbswk.hbs.edu/item/6600.html 